\title{
Radiation Performance of Commercial SiGe HBT BiCMOS High Speed Operational Amplifiers
}

\author{
Dakai Chen, Member, IEEE, Jonathan Pellish, Member, IEEE, Anthony Phan, Hak Kim, Sam Burns, Rafi Albarian, \\ Bruce Holcombe, Bradley Little, James Salzman, Paul Marshall, Member, IEEE, and Kenneth LaBel, Member, \\ IEEE
}

\begin{abstract}
We present results on heavy-ion and proton irradiations for commercial SiGe BiCMOS differential amplifiers: LTC6400-20 from Linear Technology and THS4304 from Texas Instruments. We found that the devices are susceptible to heavy-ion-induced SETs, with relatively low LET thresholds $\left(\right.$ LET $\left._{\text {th }}\right)$. The LTC6400 exhibits a LET $_{\text {th }}<7.4$ $\mathrm{MeV} \cdot \mathrm{cm}^{2} / \mathrm{mg}$ for frequencies ranging from 10 to $1000 \mathrm{MHz}$. The THS4304 exhibits a $\mathrm{LET}_{\text {th }}<4.4 \mathrm{MeV} \cdot \mathrm{cm}^{2} / \mathrm{mg}$ at $200 \mathrm{MHz}$; the LET $_{\text {th }}$ decreases with increasing frequency. The SET crosssections increase with increasing operating frequency. The significance of the SETs also increases with frequency. The SETs at $1000 \mathrm{MHz}$ erase several signal cycles. We also found that the LTC6400 is relatively robust against 198 and $54 \mathrm{MeV}$ protons. We did not observe angular sensitivity from the proton irradiations.
\end{abstract}

\section{INTRODUCTION}

Qilicon-germanium (SiGe) heterojunction-bipolartransistors (HBTs) are well suited for high speed microelectronic applications. SiGe HBTs utilize band gap engineering to achieve similar performance as III-V compound semiconductors, while maintaining the same $\mathrm{Si}$ CMOS fabrication processes. Therefore we benefit from the high performance, while keeping the manufacturing costs down.

Although flight systems desire radiation hardened parts, these components are often more expensive and remain several technology generations behind their commercial counterparts. As a result, space systems are utilizing more commercial-off-the-shelf (COTS) parts, especially in missions with relatively lower radiation requirements. The

Manuscript received on July 15, 2010.

This work is supported in part by the NASA Electronics Parts and Packaging program (NEPP) and the Defense Threat Reduction Agency (DTRA) under IACRO\#09-4587I.

Dakai Chen, Anthony Phan, and Hak Kim are with MEI Technologies Inc., in support of NASA/GSFC, Greenbelt, MD, USA 20771 (phone: 301286-8595, e-mail: dakai.chen-1@nasa.gov).

Jonathan Pellish and Kenneth LaBel are with NASA/GSFC, Greenbelt, MD, USA $20771 \quad$ (email: jonathan.a.pellish@nasa.gov, kenneth.a.label@nasa.gov).

Sam Burns and Rafi Albarian are with Linear Technology Corp.,

Milpitas, CA, USA 95035 (email: sburns@linear.com,

ralbarian@linear.com).

Bruce Holcombe, Bradley Little, and James Salzman are with Texas Instruments, Inc., 6412 Highway 75 South, Sherman, Texas, USA75090 (email: salzman@ti.com).

P. Marshall is a consultant and is at Brookneal, VA 24528 USA (e-mail: PWMarshall@aol.com).
SiGe HBT technology is attractive for space applications due to its intrinsic tolerance to both ionizing and non-ionizing irradiation effects [1]-[3]. However SiGe HBT-based circuits are sensitive to single event effects (SEE), such as single event upsets (SEU) and transients (SET) [4]. Additionally, since SiGe HBT technology is often designed for high speed applications, the high operating frequency further enhances the significance of the SEUs and SETs [5], [6].

Furthermore, these high speed devices typically have low linear energy transfer (LET) upset thresholds, which can lead to vulnerability to proton irradiations [7]. Proton-induced SEEs can be a concern for orbits in proton rich environments, like the Van Allen Belt. The SEUs/SETs from protons can also exhibit angular dependence, which increases in significance as geometries become smaller [8].

Here we investigate the SEE sensitivities of commercial SiGe HBT BiCMOS operational amplifiers from different manufacturers with heavy-ion and proton irradiations.

\section{DEVICE DESCRIPTION}

The devices in this experiment include the LTC6400 differential output amplifier from Linear Technology and the THS4304 wideband amplifier from Texas Instruments. Table I. shows the device information, including the process technology, lot date code, and part function.

The LTC6400 is fabricated with the JAZZ-TOWER $0.35 \mu \mathrm{m}$ SiGe BiCMOS process. The process includes $3.3 \mathrm{~V}$ CMOS with deep trench isolations, and lateral PNP transistors. Additional options include a $5 \mathrm{~V}$ CMOS, vertical PNP transistor, and triple-well isolation.

The THS4304 is developed in Texas Instrument's BiCom3 Silicon-Germanium BiCMOS process. The process contains complementary SiGe PNP and NPN transistors, $5 \mathrm{~V}$ $0.35 \mu \mathrm{m}$ SOI CMOS logic, and trench isolation.

TABLE I.

DEVICE INFORMATION.

\begin{tabular}{|l|l|l|}
\hline & LTC6400 & THS4304 \\
\hline \multirow{2}{*}{ Manufacturer } & $\begin{array}{l}\text { Linear } \\
\text { Technology }\end{array}$ & Texas \\
& Instrument \\
\hline \multirow{3}{*}{ Process } & $\begin{array}{l}\text { JAZZ-TOWER } \\
0.35 \mu \mathrm{m} \text { SiGe }\end{array}$ & TI BiCom3SiGe \\
& BiCMOS & BiCMOS \\
\hline Lot date code & 0746 and 0705 & October, 2004 \\
\hline
\end{tabular}




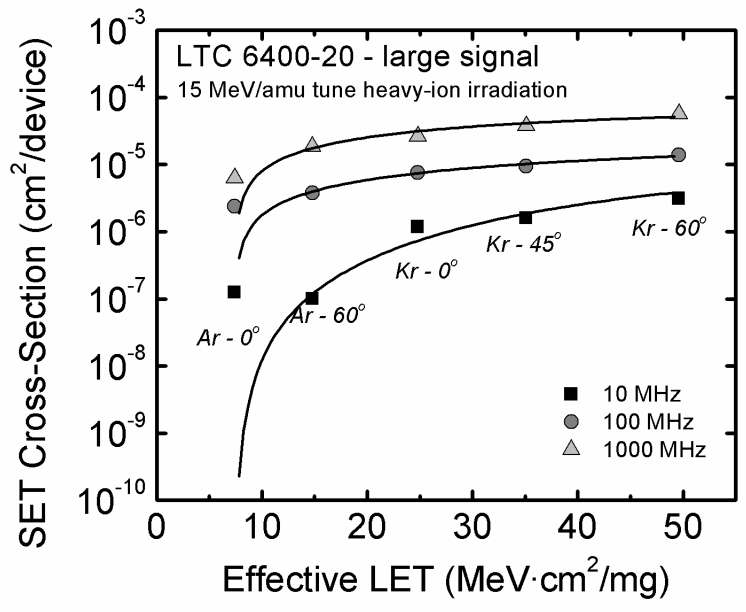

Fig. 1. Heavy-ion-induced SET error cross-sections vs. effective LET for the LTC6400 with $\mathrm{V}_{\mathrm{IN}}=140 \mathrm{mV}_{\mathrm{pp}}$ and frequencies of 10,100 , and 1000 $\mathrm{MHz}$.

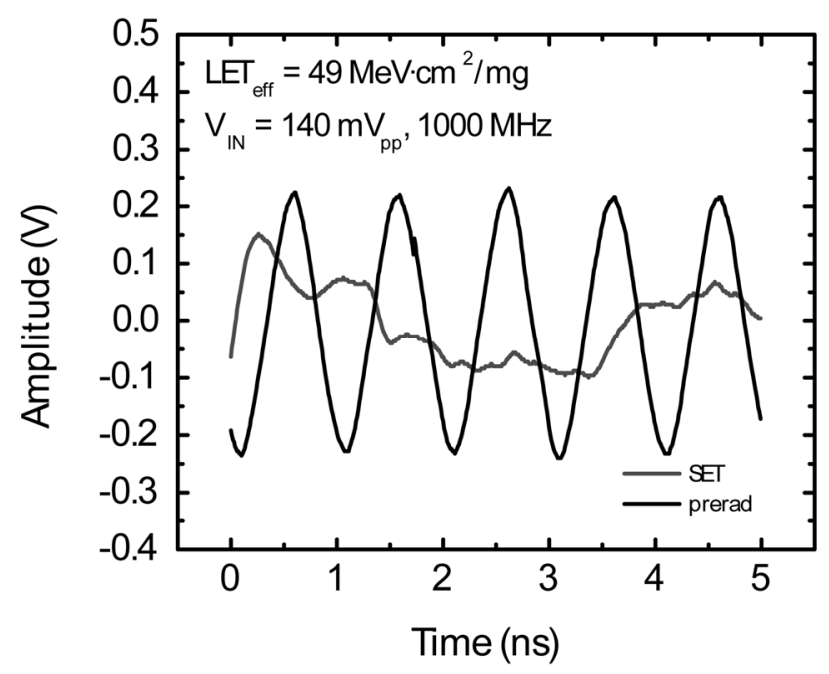

Fig. 3. Heavy-ion-induced SET characteristics for the LTC6400 operating with $\mathrm{V}_{\mathrm{IN}}=140 \mathrm{mV}_{\mathrm{pp}}$, frequency $=1000 \mathrm{MHz}$, at LET $=49 \mathrm{MeV} \cdot \mathrm{cm}^{2} / \mathrm{mg}$.

\section{EXPERIMENTAL DETAILS}

We conducted the heavy-ion irradiations at the Texas A\&M Cyclotron SEE Test Facility. The beam energy was 15 $\mathrm{MeV} / \mathrm{amu}$. The flux varied from $1 \times 10^{4}$ to $1 \times 10^{5} \mathrm{~cm}^{-2} \cdot \mathrm{s}^{-1}$. Table II lists the ion species used in the experiments, with their respective values for energy, linear energy transfer, and penetration range in silicon. The heavy-ion irradiations were carried out until 100 transients are observed and acquired, or up to a fluence of $2 \times 10^{7} \mathrm{~cm}^{-2}$. The proton experiment was conducted at the Indiana University Cyclotron Test Facility. The beam energy was $198 \mathrm{MeV} / \mathrm{amu}$. Various angles were used during the irradiations.

During the irradiation runs, an RF generator provides a high frequency sinusoidal signal to the device input. A digital oscilloscope monitors the output. A computer controls the test setup, including the device operating conditions and transient trigger levels, via LabVIEW program.

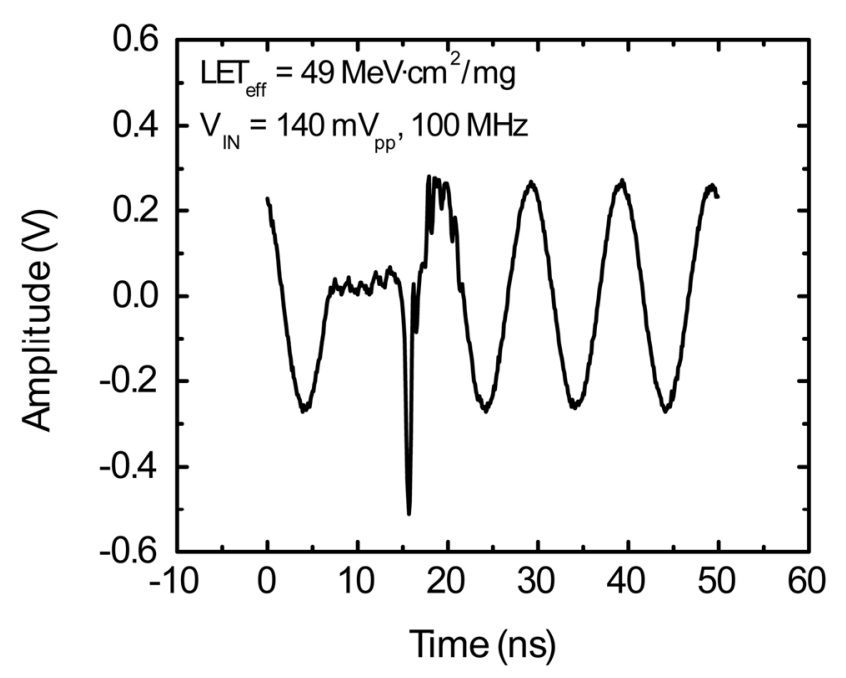

Fig. 2. Heavy-ion-induced SET characteristics for the LTC6400 operating with $\mathrm{V}_{\mathrm{IN}}=140 \mathrm{mV}_{\mathrm{pp}}$, frequency $=100 \mathrm{MHz}$, at LET $=49 \mathrm{MeV} \cdot \mathrm{cm}^{2} / \mathrm{mg}$.

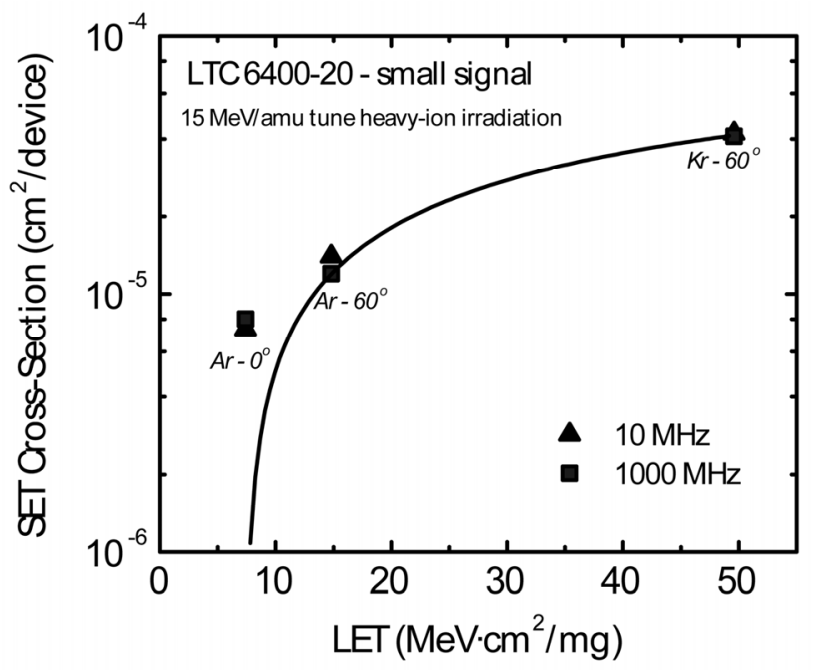

Fig. 4. Heavy-ion-induced SET error cross-sections vs. effective LET for the LTC6400 with $\mathrm{V}_{\mathrm{IN}}=2 \mathrm{mV}_{\mathrm{pp}}$ and frequencies of 10 and $1000 \mathrm{MHz}$.

TABLE II.

HEAVY-ION SPECIFICATIONS.

\begin{tabular}{|c|c|c|c|}
\hline Ion & $\begin{array}{c}\text { Peak Energy } \\
(\mathbf{M e V})\end{array}$ & $\begin{array}{c}\text { LET } \\
\left(\mathbf{M e V} \cdot \mathbf{c m}^{\mathbf{2}} / \mathbf{m g}\right)\end{array}$ & $\begin{array}{c}\text { Range in Si } \\
(\boldsymbol{\mu m})\end{array}$ \\
\hline $\mathrm{Ne}$ & 300 & 2.5 & 316 \\
\hline $\mathrm{Ar}$ & 29 & 7.4 & 229 \\
\hline $\mathrm{Cu}$ & 944 & 17.8 & 172 \\
\hline $\mathrm{Kr}$ & 152 & 24.8 & 170 \\
\hline $\mathrm{Ag}$ & 1634 & 38.5 & 156 \\
\hline
\end{tabular}

\section{HEAVY-IONS}

\section{A. $\quad$ LTC6400}

We tested the LTC6400-20 for single-ended operation. Two LTC6400 parts were irradiated at room temperature with 


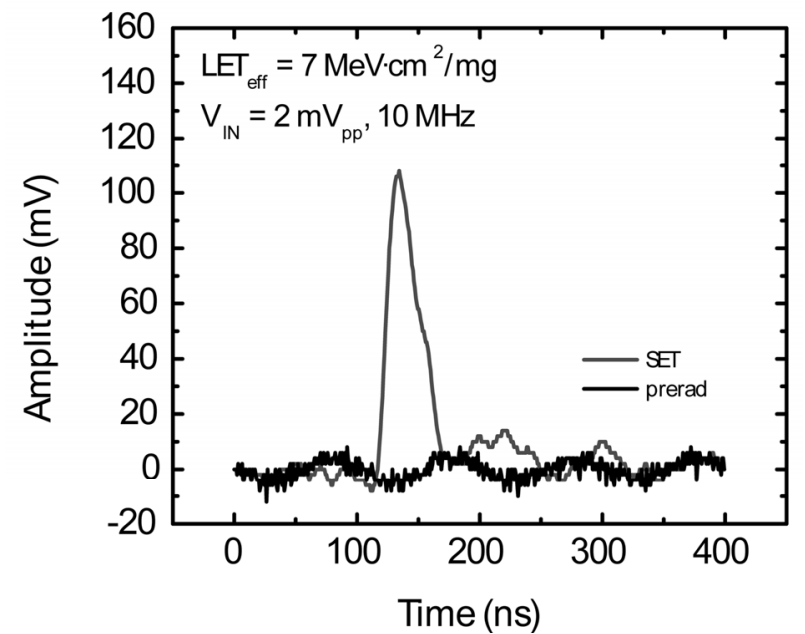

Fig. 5. Heavy-ion-induced SET characteristics for the LTC6400 operating with $V_{\mathrm{IN}}=2 \mathrm{mV}_{\mathrm{pp}}$, frequency $=10 \mathrm{MHz}$, at LET $=49 \mathrm{MeV} \cdot \mathrm{cm}^{2} / \mathrm{mg}$.

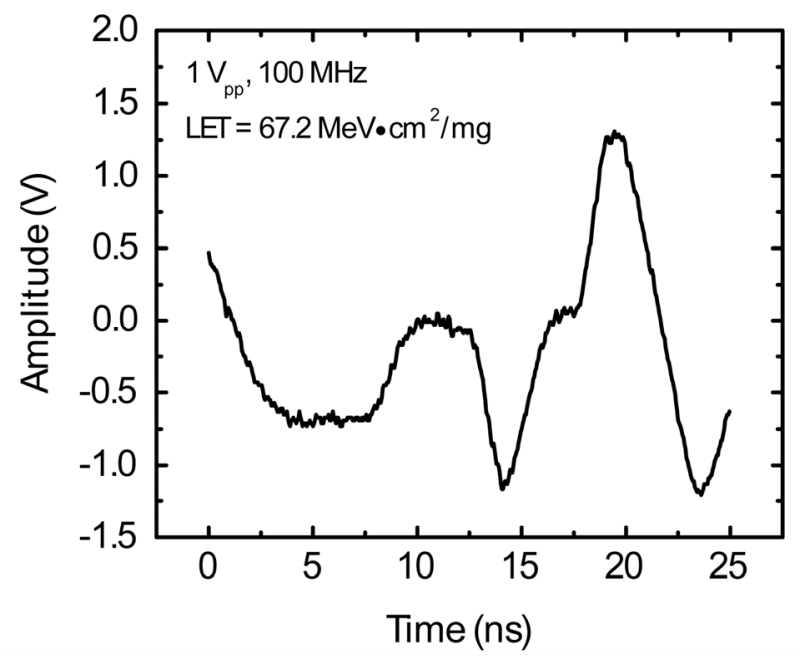

Fig. 7. Heavy-ion-induced SET characteristics for the THS4304 operating with $\mathrm{V}_{\mathrm{IN}}=800 \mathrm{mV}_{\mathrm{pp}}$, frequency $=100 \mathrm{MHz}$, at LET $=67 \mathrm{MeV} \cdot \mathrm{cm}^{2} / \mathrm{mg}$.

the devices operating at $\mathrm{V}_{\mathrm{CC}}=3 \mathrm{~V}, \mathrm{~V}_{\mathrm{CM}}=1.25 \mathrm{~V}$, sinusoidal inputs of $140 \mathrm{mV}_{\mathrm{pp}}$ (large signal) or $2 \mathrm{mV}_{\mathrm{pp}}$ (small signal), at frequencies of 10,100, and $1000 \mathrm{MHz}$. Two ion species were used for this experiment: Ar and Kr.

Fig. 1. shows the SET cross-sections from large signals at 10,100 , and $1000 \mathrm{MHz}$. We observed SET LET $_{\text {th }}<7.4$ $\mathrm{MeV} \cdot \mathrm{cm}^{2} / \mathrm{mg}$ for all frequencies of operation. The SET crosssection increases linearly with increasing frequency, partly due to reduced noise-margins and an increasing proportion of clock edges [4]-[6]. The SET LET threshold may also exhibit frequency dependence at smaller LET values.

The SET characteristics also depend on the device's operating frequency. SETs at $10 \mathrm{MHz}$ appeared as small glitches. The majority of SETs at $100 \mathrm{MHz}$ are positive- or negative-going voltage spikes, which disrupt 1 to 2 bits of the signal, as shown in FiG. 2. Fig. 3. shows a typical SET at $1000 \mathrm{MHz}$. A few of the SETs at $100 \mathrm{MHz}$ and most of the

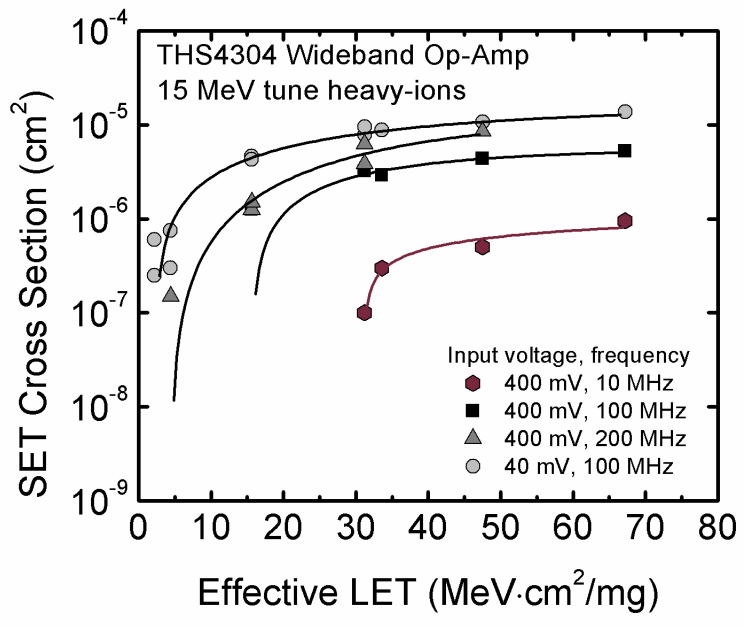

Fig. 6. Heavy-ion-induced SET cross-sections vs. effective LET for the THS4304 at various operating conditions.

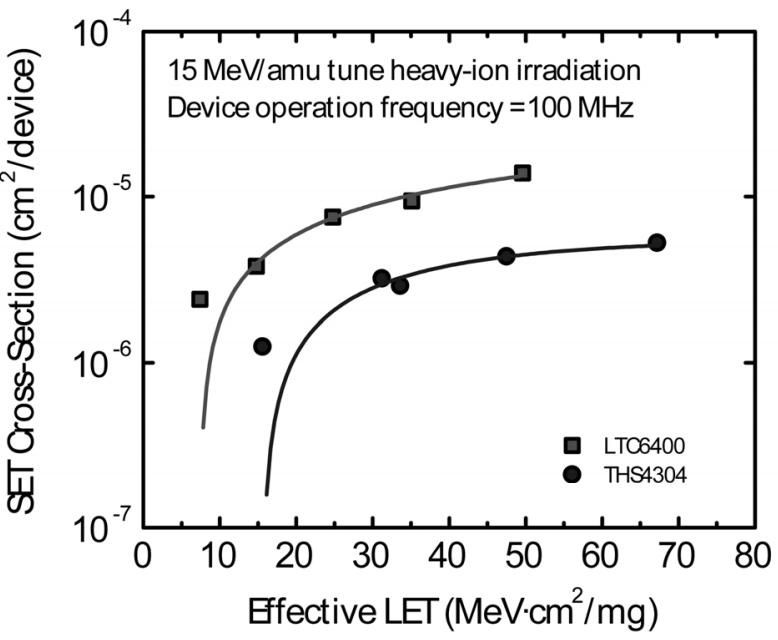

Fig. 8. Heavy-ion-induced SET cross-sections vs. effective LET for the LTC6400 and THS4304 operating at $100 \mathrm{MHz}$.

SETs at $1000 \mathrm{MHz}$ erases several signal cycles, which can significantly impact device performance.

We also evaluated the small signal performance. Unlike the large signal response, the SET cross-sections are similar for different frequencies, as shown in Fig. 4. The SET characteristics are also similar for the different frequencies. Fig. 5. shows a worst case SET at $1000 \mathrm{MHz}$. The SET has a voltage spike of $\sim 110 \mathrm{mV}$, which is approximately $20 \times$ the output's amplitude. The signal recovers from the large voltage spike after 1 cycle, but remains unstable for several cycles.

We did not observe any destructive event, such as single event latchup, during the irradiations at room temperature up to fluencies of $2 \times 10^{7} \mathrm{~cm}^{-2}$. The supply current remained relatively unchanged, at $\sim 85-90 \mathrm{~mA}$, throughout irradiation. The parts were exposed to approximately 100 $\operatorname{krad}(\mathrm{Si})$ total ionizing dose for the duration of the heavy-ion 
TABLE III.

PROTON IRRADIATION INFORMATION AND SET RESULTS.

\begin{tabular}{|c|c|c|c|c|c|c|c|c|}
\hline Run & DUT & $\begin{array}{c}\text { Incident Angle } \\
\text { (degrees) }\end{array}$ & $\begin{array}{c}\text { Beam } \\
\text { Energy } \\
(\mathrm{MeV})\end{array}$ & $\begin{array}{c}\text { Avg Flux } \\
\left(\# /\left(\mathrm{cm}^{2} \cdot \mathrm{s}\right)\right)\end{array}$ & $\begin{array}{l}\text { Fluence } \\
\left(\# / \mathrm{cm}^{-2}\right)\end{array}$ & TID (krad) & SETs & $\begin{array}{c}\text { Cross-section } \\
\sigma\left(\mathrm{cm}^{2}\right)\end{array}$ \\
\hline 31 & 3 & 0 & 198 & $5.20 \mathrm{E}+08$ & $1.00 \mathrm{E}+11$ & 18.57 & 0 & 0 \\
\hline 32 & 3 & 0 & 198 & $2.81 \mathrm{E}+09$ & $1.00 \mathrm{E}+12$ & 78.37 & 3 & $3.00 \mathrm{E}-12$ \\
\hline 33 & 3 & 60 & 198 & $2.98 \mathrm{E}+09$ & $1.00 \mathrm{E}+12$ & 138.17 & 8 & $8.00 \mathrm{E}-12$ \\
\hline 34 & 3 & 90 & 198 & $2.62 \mathrm{E}+09$ & $1.00 \mathrm{E}+12$ & 197.97 & 8 & $8.00 \mathrm{E}-12$ \\
\hline 35 & 3 & 0 & 198 & $2.91 \mathrm{E}+09$ & $1.00 \mathrm{E}+12$ & 257.77 & 15 & $1.50 \mathrm{E}-11$ \\
\hline 1 & 4 & 0 & 198 & $6.40 \mathrm{E}+08$ & $1.00 \mathrm{E}+11$ & 5.98 & 1 & $1.00 \mathrm{E}-11$ \\
\hline 2 & 4 & 0 & 198 & $2.97 \mathrm{E}+09$ & $1.00 \mathrm{E}+12$ & 60.00 & 3 & $3.00 \mathrm{E}-12$ \\
\hline 3 & 4 & 0 & 198 & $3.02 \mathrm{E}+09$ & $4.00 \mathrm{E}+12$ & 239.00 & 4 & $1.00 \mathrm{E}-12$ \\
\hline 4 & 4 & 0 & 198 & $3.00 \mathrm{E}+09$ & $4.90 \mathrm{E}+11$ & 3.34 & 1 & $2.04 \mathrm{E}-12$ \\
\hline 5 & 4 & 0 & 198 & $2.90 \mathrm{E}+09$ & $2.00 \mathrm{E}+12$ & 120.00 & 9 & $4.50 \mathrm{E}-12$ \\
\hline 6 & 4 & 0 & 198 & $3.03 \mathrm{E}+09$ & $6.20 \mathrm{E}+11$ & 37.00 & 3 & $4.84 \mathrm{E}-12$ \\
\hline 7 & 4 & 0 & 198 & $3.25 \mathrm{E}+09$ & $2.00 \mathrm{E}+12$ & 129.00 & 5 & $2.50 \mathrm{E}-12$ \\
\hline 8 & 4 & 0 & 198 & $3.10 \mathrm{E}+09$ & $5.00 \mathrm{E}+12$ & 300.00 & 19 & $3.80 \mathrm{E}-12$ \\
\hline 9 & 4 & 0 & 198 & $2.96 \mathrm{E}+09$ & $5.00 \mathrm{E}+12$ & 300.00 & 20 & $4.00 \mathrm{E}-12$ \\
\hline 10 & 4 & 0 & 198 & $3.10 \mathrm{E}+09$ & $1.50 \mathrm{E}+11$ & 1.20 & 0 & 0 \\
\hline 11 & 4 & 0 & 198 & $3.04 \mathrm{E}+09$ & $5.00 \mathrm{E}+12$ & 300.00 & 16 & $3.20 \mathrm{E}-12$ \\
\hline 13 & 5 & 0 & 54 & $1.66 \mathrm{E}+09$ & $1.00 \mathrm{E}+12$ & 150.00 & 1 & $1.00 \mathrm{E}-12$ \\
\hline 14 & 5 & 0 & 54 & $1.69 \mathrm{E}+09$ & $1.00 \mathrm{E}+12$ & 300.00 & 0 & 0 \\
\hline 15 & 5 & 60 & 54 & $1.69 \mathrm{E}+09$ & $2.00 \mathrm{E}+12$ & 600.00 & 1 & $5.00 \mathrm{E}-13$ \\
\hline 16 & 5 & 90 & 54 & $1.64 \mathrm{E}+09$ & $2.00 \mathrm{E}+12$ & 900.00 & 0 & 0 \\
\hline 17 & 5 & 0 & 198 & $1.46 \mathrm{E}+00$ & $2.00 \mathrm{E}+12$ & 1020.00 & 5 & $2.50 \mathrm{E}-12$ \\
\hline
\end{tabular}

irradiation, with no significant effect on the SET crosssection.

\section{B. THS4304}

Two THS4304 parts were irradiated with the devices operating with $\mathrm{V}_{\mathrm{CC}+}=2.5 \mathrm{~V}, \mathrm{~V}_{\mathrm{CC}-}=-2.5 \mathrm{~V}$, sinusoidal $\mathrm{V}_{\text {in }}=$ $800 \mathrm{mV}_{\mathrm{pp}}$ or $100 \mathrm{mV}_{\mathrm{pp}}, 10,100$, and $200 \mathrm{MHz}$. Three ion species were used for this experiment: $\mathrm{Ne}, \mathrm{Cu}$, and $\mathrm{Ag}$. Fig. 6. shows the SET cross-sections vs. LET, with the devices operating in various conditions. The SET LET $_{\text {th }}$ and error cross-sections vary with the LET, the operating frequency, and the input signal.

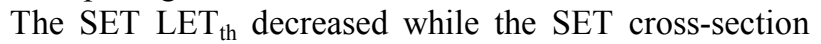
increased, with increasing frequency for large signals $\left(1 \mathrm{~V}_{\mathrm{pp}}\right)$. The SET LET $_{\text {th }}$ and cross-sections for the small signal (100 $\mathrm{mV}_{\mathrm{pp}}$ ) showed negligible frequency dependence, similar to the LTC6400 part. The SET LET th is less than 4.4 $\mathrm{MeV} \cdot \mathrm{cm}^{2} / \mathrm{mg}$ at $200 \mathrm{MHz}$. Fig. 7. shows a typical SET from a large signal at $100 \mathrm{MHz}$. Approximately $1-2$ data bits are affected by an SET at this frequency, similar to the LTC6400. We did not observe any destructive event.

Fig. 8. shows the SET cross-sections for the THS4304 and LTC6400, with both devices operating at $100 \mathrm{MHz}$. We note that there are differences in the operation conditions. The magnitudes of the input signals and signal gains from the application circuits were $\mathrm{V}_{\mathrm{IN}}=140 \mathrm{mV}_{\mathrm{pp}}, 20 \mathrm{~dB}$ and $\mathrm{V}_{\mathrm{IN}}=$ $800 \mathrm{mV}_{\mathrm{pp}}, 6 \mathrm{~dB}$ for the LTC6400 and THS4304, respectively.

The SET cross-section for the LTC6400 is about half of one magnitude larger than that of the THS4304. The SET $\mathrm{LET}_{\text {th }}$ for the THS4304 $\left(<15.6 \mathrm{MeV} \cdot \mathrm{cm}^{2} / \mathrm{mg}\right)$ is also higher than that of the LTC6400 $\left(<7.4 \mathrm{MeV} \cdot \mathrm{cm}^{2} / \mathrm{mg}\right)$ at $100 \mathrm{MHz}$.

Fig. 8. offers a quick comparison of the relative SEE performances of the state-of-the-art $\mathrm{SiGe}$ operational amplifiers of similar technology node. The LTC6400 and the THS4304 have considerable differences in their processes, designs, and functions, which may lead to the differences in their radiation performance. For example the THS4304 utilizes SOI CMOS, which is known to be more robust against SEEs relative to Bulk CMOS. The SET susceptibility also depends on many other elements. As described previously, the different operation conditions for the input signals may also influence the SEE sensitivity.

\section{PROTONS}

We also examined the SEE susceptibility of the LTC6400 with high energy protons. We tested 3 parts throughout two separate proton tests. The parts operated with $\mathrm{V}_{\mathrm{IN}}=140 \mathrm{mV}_{\mathrm{pp}}$ sinusoidal input signal and various frequencies. We observed SETs only at $200 \mathrm{MHz}$. We irradiated the first part (DUT3) with $198 \mathrm{MeV}$ protons, at $0^{\circ}$, $60^{\circ}, 90^{\circ}$, and again at $0^{\circ}$ incident angles, up to a total proton 


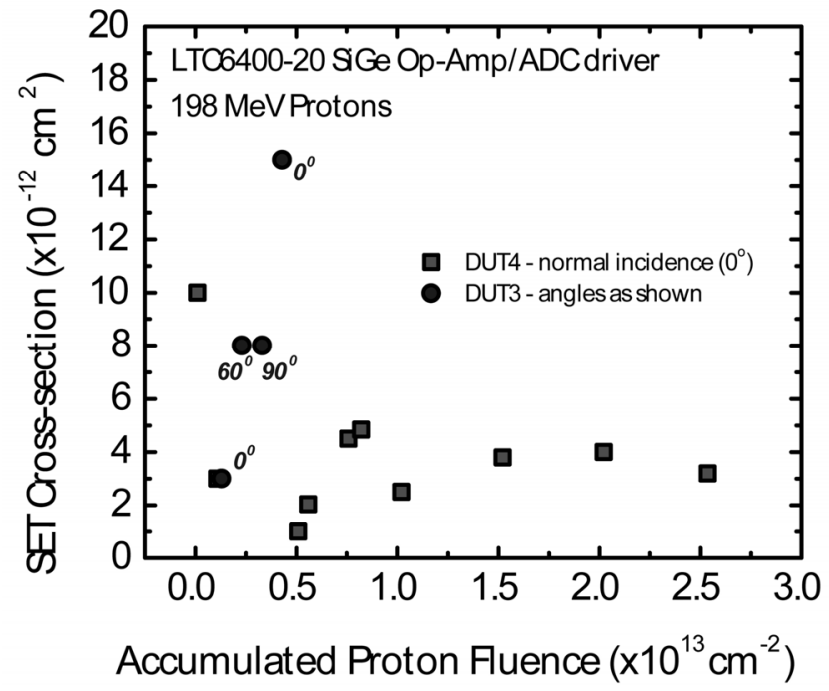

Fig. 9. Proton-induced SET cross-sections vs. accumulated proton fluence for the LTC6400 operating with $\mathrm{V}_{\mathrm{IN}}=140 \mathrm{mV}_{\mathrm{pp}}$ and $200 \mathrm{MHz}$.

fluence of $\sim 4.3 \times 10^{12} \mathrm{~cm}^{-2}$. The proton fluence for each run was $1 \times 10^{12} \mathrm{~cm}^{-2}$. The initial $0^{\circ}$ incident run produced 3 SETs. The following runs at $60^{\circ}$ and $90^{\circ}$ produced 8 SETs each. The final run at $0^{\circ}$ produced 15 SETs. Fig. 9. shows the cross-sections vs. accumulated proton fluence, with noted incident angles.

The increase in SET error cross-sections from $0^{\circ}$ to $60^{\circ}$ is unlikely due to angular effects that can result from nuclear elastic scattering or spallation reactions [7], since the final $0^{\circ}$ incident run produced a larger cross-section than the angular irradiations and the initial normal incident run. The data trend suggests that the increase in error cross-section is possibly due to increases in accumulated TID and/or displacement damage.

We irradiated a second part (DUT4) with $198 \mathrm{MeV}$ protons at normal incidence up to a total fluence of $2.5 \times 10^{13}$ $\mathrm{cm}^{-2}$ to examine the effect of increasing proton dose. As shown in Fig. 9., the cross-section increases notably from a proton fluence of approximately $5 \times 10^{13} \mathrm{~cm}^{-2}$ to $8.2 \times 10^{13}$ $\mathrm{cm}^{-2}$, but then decreases. There is significant scatter in the SET cross-sections. Therefore the dataset here is consistent with a Poisson distribution with allowable error deviations. For example the first data point is based on 1 SET.

The notable difference in the magnitudes of the SET cross-sections between the two parts may also be the result of the error deviations and/or part-to-part variations, as the parts have different lot-date-codes.

We also irradiated a third part with $54 \mathrm{MeV}$ protons at $0^{\circ}, 60^{\circ}$ and $90^{\circ}$ incident angles. We observed a maximum of 1 SET up to $2 \times 10^{12} \mathrm{~cm}^{-2}$ proton fluence at each angle. So the part is very robust against $54 \mathrm{MeV}$ protons, with no signature of angular sensitivity.

\section{CONCLUSION}

We have evaluated the performance of two state-of-theart commercial SiGe HBT-based operational amplifiers in heavy-ion and proton radiation environments. The devices were sensitive to heavy-ion-induced SETs, with relatively low LET thresholds. The SET cross-sections increased with increasing frequency, similar to previous studies [5], [6]. The significance of the SETs also increased with increasing frequency. The most significant transients at $1 \mathrm{GHz}$ for the LTC6400 erased several cycles of the output signal. The small signal response did not exhibit frequency dependence for either of the devices.

Additionally the LTC6400 was robust against high energy protons, with relatively low SET cross-sections. We observed sharp increases in the cross-section at early stages of irradiation for each of the two parts. The increase in crosssection may be due to the increase in degradation from accumulated TID/DD. However the significant scatter in the dataset suggests that the SET cross-sections more likely follow a Poisson distribution, and do not correlate strongly with accumulated dose. The significant difference in the SET cross-sections for the two parts is also consistent with the large data scatter. In addition the different lot date codes of the parts may also contribute to the variability of their radiation response.

\section{ACKNOWLEDGEMENT}

This work was supported in part by the NASA Electronic Parts and Packaging Program (NEPP) and the Defense Threat Reduction Agency (DTRA) under IACRO\# 10-4977I.

The authors would like to thank Ray Ladbury for his insights on statistical analysis.

\section{REFERENCES}

[1] J. A. Babcock, J. D. Cressler, L. S. Vempati, S. D. Clark, R. C. Jaeger, and D. L. Harame, "Ionizing radiation tolerance of highperformance SiGe HBT's grown by UHV/CVD," IEEE Trans. Nucl. Sci., vol. 42, Dec. 1995, pp. $1558-1566$.

[2] J. Roldán, W. E. Ansley, J. D. Cressler, S. D. Clark, and D. NguyenNgoc, "Neutral radiation tolerance of advanced UHV/CVD SiGe NBTs," IEEE Trans. Nucl. Sci., vol. 44, Dec. 1997, pp. 1965 - 1973.

[3] J. D. Cressler, "On the potential of SiGe HBTs for extreme environment electronics," Proceedings of IEEE, vol. 93, Sep. 2005, pp $1559-1582$.

[4] P. W. Marshall, M. A. Carts, A. Campbell, R. Ladbury, R. A. Reed, C. J. Marshall, S. Currie, D. McMorrow, S. Buchner, C. Seidleck, P. Riggs, K. Fritz, B. Randall, and B. Gilbert, "A comparative study of heavy-ion and proton-induced bit-error sensitivity and complex burst-error modes in commercially available high-speed $\mathrm{SiGe}$ BiCMOS," IEEE Trans. Nucl. Sci., vol. 51, Dec. 2004, pp. 3457 3463.

[5] P. W. Marshall, M. A. Carts, A. Campbell, D. McMorrow, S. Buchner, R. Stewart, B. Randall, B. Gilbert, and R. A. Reed, "Single event effects in circuit-hardened SiGe HBT logic at gigabit per second data rates," IEEE Trans. Nucl. Sci., vol. 47, Dec. 2000, pp. $2669-2674$

[6] R. A. Reed, M. A. Carts, P. W. Marshall, C. J. Marshall, S. Buchner, M. La Macchia, B. Mathes, and D. McMorrow, "Single event upset cross sections at various data rates," IEEE Trans. Nucl. Sci., vol. 43, Dec. 1996, pp. $2862-2867$.

[7] P. E. Marshall and C. J. Marshall, "Proton effects and test issues for satellite designers," in Proceedings IEEE NSREC - Short Course, 1999.

[8] R. A. Reed, P.W. Marshall, H. S. Kim, P. J. McNulty, B. Fodness, T. M. Jordan, R. Reedy, C. Tabbert, M. S. T. Liu, W. Heikkila, S. Buchner, R. Ladbury, and K. LaBel, "Evidence of angular effects in proton-induced single-event upsets," IEEE Trans. Nucl. Sci., vol. 49, Dec. 2002, pp. 3038 - 3043. 